\title{
Assertions and Their Justification: Demonstration and Self-Evidence
}

\begin{abstract}
In Frege's epistemic account of logic, the notions assertion, justification and being evident play a central role. Although the notion of judging agent plays an important role in the explanation of these notions, this does not mean that Frege's logic is committed to a form of psychologism. How can we use Frege's account of these notions to illuminate the notions of demonstration and being evident in Constructive Type Theory (CTT)? As the judging agent also plays a role in CTT, how can it prevent a form of psychologism? Although the notion of demonstration cannot be understood without invoking a judging agent, such a judging agent is a first person, which is not to be understood as an empirical subject. And similarly for being evident. The latter notion is often taken to imply a form of psychologism. Although the appeal to the notion of being evident involves a form of fallibilism, the notion is normative, and therefore not psychological. It can thus be used to account for a justification of the inference rules.
\end{abstract}

\section{Introduction}

In Constructive Type Theory (CTT), epistemic notions like judgement and demonstration, play a central role. Is it possible to give an epistemic foundation of logic, without being committed to a form of psychologism? Frege's epistemic account of logic (section 2) is taken as a starting-point to see whether he is able to prevent a form of psychologism, given the central role of the judgement stroke, the judging agent, justification and being evident in his logic. In section 3, the tradition notion of judgement is related to modern accounts of assertion, and it turns out that both judgement and assertion can be understood in epistemic terms. Both in Frege's writings and in CTT, the act of demonstration, a special kind of act of judgement, plays a central role. Can we give a non-psychological account of such acts? Finally, in section 4, we have to appeal to the idea that some of our judgements and inference rules are self-evident. Although most readers of Frege think of self-evidence as a property of Thoughts, it is rather the being evident of the truth of a thought to a certain agent that is relevant to Frege's writings and to CTT. I will therefore speak of being (self-)evident rather than of self-evidence. As claims to being evident

Maria van der Schaar, Institute for Philosophy, Leiden University, The Netherlands, e-mail: m.v.d.schaar@phil.leidenuniv.nl

DOI 10.1515/9783110218091-12 
are fallible, Wittgenstein seems to be right in his criticism of Frege: "If, from a proposition being evident to us, it does not follow that it is true, then its being evident is also not a justification for our belief in its truth." (TLP 5.1363, translation by R.H. Schmitt). Is it possible to deal with the notion of being evident in a way that is not psychologistic?

\section{Frege on Judgement, Demonstration and Being Self-Evident}

In Frege's logic, the threat of psychologism is not only introduced by the notion of justification (Rechtfertigung), but also by the mere presence of the judgement stroke. It seems that Wittgenstein is right when he says that the judgement stroke in Frege's ideography only shows that Frege holds the relevant proposition to be true (TLP 4.442). Frege himself seems to confirm this reading: "With this judgement stroke I close a sentence, [...] and the content of the sentence thus closed I assert as being true by the same sign.” (Frege 1896: 232, orig. 377; cf. Frege 1891: orig. 22). The role of the judgement stroke is thus related to the first person in Frege's ideography, but this does not mean that the judgement is about Frege, or a process in the asserter's mind. For, that the content of the judgement is true, is independent of the knowing agent. ${ }^{1}$ Within the ideography, the use of the judgement stroke indicates that the content is acknowledged to be true. As truth is independent of the judging agent, the empirical fact that I make the judgement is irrelevant to the truth or falsity of the content. Furthermore, one can fully understand the assertion without knowing who made the assertion. Fully understanding the assertion is rather to make the judgement oneself, as a first person. ${ }^{2}$ Essential to logic is the truth claimed in the act of judgement, truth as we use it in our practice of judgements and inferences, for logic aims at the laws of truth. Frege, though, explicitly claims in "My Basic Logical Insights [1915]" that the essence of logic cannot be found in the word "true", but lies in the assertive force (NS: 272; PW: 252). Apart from using the judgement stroke in front of a sentence expressing what we take to be a law, within the ideography, there is no other way for us to say what the laws of truth are. A truth-predicate is not able to do this, for a sentence of the form "so and so is true" need not be

1 "Gewiss ist das Urteilen (das als wahr anerkennen) ein innerer seelischer Vorgang; aber dass etwas wahr ist, ist unabhänging vom Erkennenden, ist objektiv. Wenn ich etwas als wahr behaupte, will ich nicht von mir sprechen, von einem Vorgang in meiner Seele.” (WB: 126f.)

2 The notion of first person is essential for understanding the role of the judgement stroke in Frege's ideography, see (Schaar 2018). 
asserted. When Frege has determined that a Thought is a logical law, he writes down a Begriffsschriftsatz, an ideographical theorem, which is not a name, but an assertion, and he needs the judgement stroke to indicate that it is.

For his logicist project Frege has not only to define the arithmetical concepts in logical terms. He also has to show that these definitions render the arithmetical theorems demonstrable by logical means alone. Frege's logicist project is avowedly epistemic, for the central question is: What is the epistemic nature of the demonstrated laws of arithmetic (GG: vii)? This question can only be answered when we have made everything in our demonstrations explicit, and, in particular, for good overview have determined a small number of basic laws (Urgesetze, GG: vi). In Die Grundlagen der Arithmetik, Frege formulates his logicist thesis in terms of a notion of analyticity that is explained in epistemic terms. Whether the judgement is analytic depends on the "justification" of the judgement (die Berechtigung der Urteilsfällung, GLA §3). A truth is analytic, if and only if the justification or demonstration (Beweis) of our judgement can be given by logical laws, definitions and their known presuppositions, and logical inference alone. The notion of analytic truth in these passages is an epistemic one, because Frege is speaking here of theorems, justification, and judgement.

Does Frege's use of his notion of justification of a judgement constitute a form of psychologism? In the Preface to the Begriffsschrift, Frege writes that the question how we arrived at a certain judgement is to be sharply separated from the question how in the end our judgement is most securely to be grounded. ${ }^{3}$ Whereas the way we arrive at a certain truth may differ for different people, a grounding justification is in principle the same for every agent making the judgement. With a reference to Leibniz in section 17 of the Grundlagen, Frege presupposes a natural order of truths. The justifications of our judgements thus have to correspond to a metaphysical proof-structures in the independent "Third" realm. ${ }^{4}$ This forms a contrast with the earlier passage in the Grundlagen on analyticity, where Frege gave a purely epistemic account of judgement and justification. In fact, this purely epistemic account accords better with Frege's view that metaphysics follows logic, or as the master puts it himself: "Ich halte es für ein sicheres Anzeichen eines Fehlers wenn die Logik Metaphysik und Psychologie nöthig hat, Wissenschaften, die selber der

3 "Es kann daher einerseits nach dem Wege gefragt werden, auf dem ein Satz allmählich errungen wurde, andrerseits nach der Weise, wie er nun schliesslich am festesten zu begründen ist.” (Bs, Preface; cf. GLA §3).

4 I thank Göran Sundholm for pointing out this tension to me. See also (Sundholm 2011 and Shapiro 2009). Burge 1998 does not see a tension here in Frege's writings, and rather explains the epistemic notions of judgement and justification in terms of objective proof-structures, which are independent of the judging agent, at least if conceived as human agent. 
logischen Grundsätze bedürfen.” (GG: xix). Neglecting the metaphysical presupposition, one may say that if a demonstration is given for a judgement, each judging agent should be able to follow the inference steps, insofar as he has acknowledged the rules of inference and definitions used. In this sense, these demonstrations are not accidental ways in which others may have accidentally come to these truths (GLA §3). These demonstrations do not only have the aim to secure the truth of these conclusions, but also give us an insight into the dependency of truths among each other (GLA §2; cf. NS:171, 220). As Frege puts it in the Begriffsschrift, the way truths depend on each other becomes clear if one demonstrates complex truths from more simple ones (Bs §13). These dependency relations are commonly read in terms of a total ordering of propositions by means of their postulated metaphysical proof-structures, but they can also be read in an epistemic way (cf. An. Post.: 72a and ÜG §1). To see the dependency relations between truths, one has to demonstrate the less general truths by means of more general laws (GLA §4). In the Grundlagen, new demonstrations become possible, when the content of the judgement is analysed in a new way, showing itself in new definitions. The more we are able to demonstrate, the fewer truths we have to take to be undemonstrable.

If one would thus have demonstrated the arithmetical laws from a certain group of basic laws, the important question remains: What is the epistemic nature of these basic laws? What makes one entitled to use the judgement stroke in front of sentences expressing these basic laws? These most general laws neither can nor need be demonstrated, as Frege repeats the traditional phrase going back at least to Leibniz (GLA §3). But, if they cannot be demonstrated, how can they be known? Such a truth is known insofar as it is immediately evident (unmittelbar klar, unmittelbar einleuchtend, GLA §5). Traditionally, one makes a distinction between mediately evident judgements, which can be seen to be true by a demonstration, and immediately evident judgements, which can be seen to be true without the mediation of any further judgement. In the latter case, I will simply call the judgement evident, or (self-)evident. Here, the judgement is made on the basis of a single act, or deed, of knowing (Erkenntnisthat, GG: vii). "Immediacy" should not be understood as immediate in time; being obvious can be characterised as being immediate in time, but obviousness is a psychological notion, as we will see below, and cannot be used to elucidate the notion of being (self-)evident. What is the nature of this act of seeing or insight (das Einleuchten): is it logical or of an intuitive nature (logisch oder anschaulich, GLA §90)? The crucial question for logicism is whether this act of knowing involves a spatial or time intuition (Anschauung), or whether the act is based on a purely conceptual insight. In order to vindicate logicism, the basic laws from which the arithmetical laws are demonstrated have to be logical laws, that is, they have to be knowable by conceptual means alone. And the inference-rules and definitions have to be purely logical, as well. 
In the Begriffsschrift Frege uses the term "einleuchtend". Axiom I, $\vdash a \rightarrow(b \rightarrow$ $a)$ : "besagt "der Fall, wo $a$ verneint, $b$ bejaht und $a$ bejaht wird, ist ausgeschlossen." Dies leuchtet ein, da $a$ nicht zugleich verneint und bejaht werden kann.” (Bs §14). Because it can be difficult to grasp its content, Frege explains, first, the function of implication (GG §12), and then shows that on this understanding of implication the first basic logical law can be known to be true, purely on the basis of grasping its content (GG §18). Frege's arguments here can be understood as an unfolding of what implication means. The reader may thus be convinced that the sentence expressing the basic law has to be true, but the understanding part he has to do for himself. And this last epistemic part is essential for an entitlement to use the judgement stroke. We may generalise these remarks on the first axiom by saying that a basic law is a logical law, if and only if one is entitled to judge it purely on the basis of grasping its content. ${ }^{5}$

At the time of writing the Grundgesetze, Frege held Basic Law V to be a logical law (GG: vii), and later confesses that it was not as evident (einleuchtend, GG: 253, Nachwort) as the others. This must mean that he never fully grasped its content, and that he realizes this, now that he knows about Russell's paradox. Writing about his judgement in the past, he is describing a psychological fact about the degrees of perceived clarity. Frege understands that he is not entitled to use the judgement stroke in front of the sentence expressing Basic Law V, and withdraws his former assertion.

Wittgenstein thus seems to be right: "Wenn daraus, dass ein Satz uns einleuchtet, nicht folgt, dass er wahr ist, so ist das Einleuchten auch keine Rechtfertigung für unseren Glauben an seine Wahrheit.” (TLP 5.1363; the translation can be found in section 1). Is being evident then a psychological notion?

For Frege, being evident insofar as it plays a role in our knowing the basic laws is not a psychological notion. It is neither to be identified with (1) the mental state of conviction; nor with (2) obviousness; and it does not allow for (3) degrees. Concerning (1), Frege writes: "In mathematics one cannot be satisfied with the fact that something is evident (dass etwas einleuchte), that one is convinced of something." (NS: 221; compare GLA §90). ${ }^{6}$ We are strongly convinced of our prejudices, but they are not known: they are not self-evident. The epistemic value of

5 As Frege puts it in his very late paper Gedankengefüge, the truth of a basic law of logic is immediately evident on the basis of the sense of its expression: "(weil) die Wahrheit eines logischen [Grund] Gesetzes unmittelbar aus ihm selbst, aus dem Sinne seines Ausdrucks einleuchtet.” (Frege 1923: 50)

6 As this passage shows, Frege does not have any technical terminology relating to the notion of being evident; we always have to invoke the context in order to determine the meaning of terms such as "einleuchtend" and "selbstverständlich". 
being convinced is derived from our judgement being justified or evident. (2) A truth is obvious if it is patent: we do not need time to make the judgement. The truth that $2+3=5$ is obvious, but not self-evident, for we can give a demonstration for it. Self-evident truths may be obvious, but they may also not be obvious at all. When writing the Grundgesetze, Frege did not take Basic Law V to be obvious, but he thought it would be possible to make it evident by conceptual means alone. Finally, (3) as Frege puts it, "Whether the falsity of a Thought is easy or difficult to recognize is not relevant to logic.” (Frege 1923: 42). Such degrees may differ for different people, and should be irrelevant when considering the notion of being evident. Just as we cannot speak of degrees of demonstration or knowledge, so we cannot speak of degrees of being evident. Being evident, for Frege, has to be epistemic, and epistemology is to be sharply separated from psychology (Frege 1885: orig. 329). Since being evident is an epistemic notion, it is normative. It is precisely for this reason that we can make mistakes regarding the question whether the truth of a judgeable content (or a Thought) is evident.

The question whether being evident is a psychological notion may be illuminated by relating it to the question how numbers are given to us. The latter is not a question that can be investigated by empirical means, whether of a psychological or other nature. The objects of arithmetic are not given to us as objects external to us (als etwas Fremdes) that can only be known by means of the senses; these objects are independent of the individual judger, but at the same time are immediately given to us as reasoning or judging agents (unmittelbar der Vernunft gegeben, GLA $\S 105)$. It is precisely for this reason that the arithmetical laws are not subjective.

For Frege, to say that a Thought is true, or that its truth is demonstrated or self-evident is not predicating a property of that Thought. Its being true is not an empirical phenomenon to be described by means of a predicate. These normative notions rather show themselves in our first-person acts of judgement, inference and demonstration, and in the use of the ideographical judgement stroke. The fact that these acts are fallible does not make them subjective or psychological. For, when we use a judgement stroke in front of a sentence expressing a basic law, we implicitly claim that any judging agent can, in principle, make the truth of the Thought known to himself. Although these notions cannot be understood without invoking the notion of judging agent, this does not make them subjective or psychological. 


\section{Assertion and Demonstration}

The idea that logic is an epistemic project is an old one (Sundholm 2009), although since Wittgenstein's Tractatus and the meta-mathematical turn, epistemological questions seem to have been banished from the realm of logic. Swedish ProofTheory and the Dutch tradition of mathematical intuitionism, though, have retained some elements of the old conception of logic. Today an epistemic view of logic is advocated by Per Martin-Löf in his Constructive Type Theory (CTT), where logic is to comprise the theory of assertion and (epistemic) inference (Martin-Löf 2015).

In a constructivist account of logic, as indeed for Frege, each inference step needs to be knowledge preserving, that is, the act of inference needs to be epistemic. If the premises are actually known, the act of inference is an act of demonstration, that is, an explicitly epistemic notion. Before explaining this point let me first show what the role of judgement is in logic in general, and in CTT in particular, and to what extent judgement is an epistemic notion. As inferences bring us from judgements made to new judgements, the notion of judgement is essential to logic. As there is, from a logical point of view, no distinction between judgement and assertion, I will speak of assertion, instead, because this makes it possible to relate the idea that judgement is relevant for logic to current discussions on assertion.

At first sight, it seems that one is entitled to make an assertion, only if the asserted content is true. This seems to be confirmed by Frege's thesis that judgement is the acknowledgement of the truth of a Thought. A disadvantage of this view is that the asserter is often not able to determine whether the content is true, at least, if truth is understood in realistic terms. It is therefore sometimes proposed that one is entitled to make an assertion if and only if one is sincerely convinced of the truth of its content, if one feels it to be true. The asserter is thus able to determine whether he is entitled to make the assertion. This demand on assertion seems not to be strict enough, for an interlocutor is entitled to ask "How do you know that?", when an assertion is made. ${ }^{7}$ When George W. Bush asserted that there are weapons of mass destruction in Iraq, he was, perhaps, sincerely convinced of the truth of what he asserted, but this made him not entitled to make the assertion, for he did not know that there were such weapons. Such an account of assertion would make assertion, and thereby judgement, a psychological notion. The logical or epistemic notion of judgement and the psychological notion of belief must be kept apart (see Schaar 2018). Are we then to defend a knowledge account of assertion, as Timothy Williamson 2000 has done? If knowledge entails truth, the same argument that holds against the truth-account of assertion can be raised here. Instead, one may

7 See Sundholm 1988. 
argue that the "How do you know that?' question can be answered by giving a justification for one's assertion. One may thus adopt a justification account of assertion, which constitutes an epistemic account of assertion and judgement. One is entitled to make an assertion only if one is able to give a justification for it. ${ }^{8}$ Within Frege's ideography, it seems that one is entitled to use the judgement stroke only if what is asserted is known or justified, either through an act of demonstration or through an act of immediate insight. The judgement stroke would thus present an implicit knowledge-claim. All assertions can be understood as preceded by "I know that". Such a claim to knowledge is not a part of what is asserted; it is not part of the descriptive content. It has rather a performative function.

What would count as a justification for an assertion can be determined by grasping the meaning of the declarative sentence that is standardly used to make the assertion. Understanding a sentence $S$ is knowing its meaning, that is, knowing what justification one must possess in order to be entitled to use an utterance of $S$ with assertive force. Meaning thus determines what counts as a justification.

There are two ways to justify a logical or mathematical thesis: One may justify it by means of an act of demonstration, based on known premises. But in order to have any epistemic value such demonstrations need to have finite length, whence they have to end in first principles. And these first principles have to be justified, too, for the demonstrations to result in knowledge. The question how the first principles are to be justified I address in the next section.

Within Constructive Type Theory, in each act of demonstration a proof-object is constructed that makes the proposition true. A judgement of the form $A$ is true is demonstrated if one has constructed a proof-object for the proposition $\mathrm{A}$, and thus has made a judgement of the form $a: \operatorname{Proof}(A)$. That is, the proof-object $a$ is a proof for proposition $A$, where proof-objects are understood as mathematical objects, or constructions (see Sundholm 1994). A judgement of the elliptical form $A$ is true thus suppresses the constructed proof-object, and is essentially of the form there exists a proof-object of $A$. A proposition is identified with the set of proof-objects that make it true, and is explained by what counts as a canonical proof-object (and by what it is for two such objects to be equal). A judgement of the form $a$ : $A$ can thus be read as proof-object $a$ is element of the set Proof $(A)$. There is an internal relation between the proposition and its proof-objects, as they define the proposition as set. If one has constructed a non-canonical proof-object for the proposition whose truth is to be demonstrated, one thereby possesses a method, or program, for obtaining a canonical proof-object. Thus, when one has constructed a proof-object, be it canonical or non-canonical, in both cases one exhibits a reason

8 I have developed such an account of assertion in Schaar 2011. 
why the proposition is true, at least, if one displays the proof-object via a judgement in fully explicit form $a$ : $\operatorname{Proof}(A)$.

The distinction between demonstratio propter quid, sometimes called "knowledge of the reason why", and demonstratio quia, sometimes called "knowledge of the fact", is a distinction at the level of demonstrations, not at the level of ontological proof-objects, as spelled out in Sundholm 2011: 69. The distinction goes back to Aristotle's Posterior Analytics, and it translates into CTT as the distinction between the full judgemental form $a$ is a proof-object for $A$ and the elliptic form $A$ is true. If someone makes an assertion without giving the proof-object, this is a judgement of the form $A$ is true. When asked "How do you know that?" he might be giving the proof-object, thereby making the judgement $a$ is a proof-object for $A$, and thus showing that he knows the reason why. If the asserter is not able to give such a ground, he has to withdraw his assertion, for his judgement has turned out to be blind. The judgemental form $A$ is true thus derives its epistemic value from the fully explicit form. We can call it knowledge, though only in a derived sense.

The distinction between the ontological notion of proof-object and the epistemic notion of act of demonstration (proof-act) is crucial for understanding that the judging agent plays an important role in Constructive Type Theory. One is entitled to assert a judgement of the form $A$ is true, only when a proof-object for $A$ is constructed in an act of demonstration. As we cannot construct infinite proofobjects in an act of demonstration, there is nothing that may entitle us to assert that a proposition for which such proof-objects would be needed is true.

As one cannot have a demonstration without someone making the demonstration, the notion of judging agent is presupposed in the notion of demonstration. Does this mean that Constructive Type Theory is committed to a form of psychologism? When I have demonstrated a thesis, that is, have justified my assertion, and have left traces on paper, or on a blackboard, my justification lies open to others. These traces or tracks can be found in mathematical texts, and today we are used to call them proofs, though in another sense then it is used above. They are traces of the act of demonstration given by the writer (Sundholm 2004: 455). By means of the traces left, the reader is able to carry out the demonstration for himself. He has to take care that he knows the premises, and that each step in the demonstration preserves knowledge. In principle, each reader is thus able to demonstrate the theorem in the same way. While there is thus no demonstration without a judging agent, each judging agent can carry out the same demonstration, as soon as he has acknowledged the first principles, definitions and rules of inference. 


\section{Judgement and Self-Evidence}

As we have seen in Frege, the basic laws are known by means of grasping their content alone; these laws are self-evident on logical, that is, conceptual grounds. Besides, on Frege's account, Modus Ponens has to be evident to the judging agent in order for him to be entitled to use the rule. The reader of Frege's ideography has to make the truth of the basic laws, and the validity of at least one inference rule evident to himself, for without an epistemic account of the inference rule(s), there will be no demonstration. If we allow for first judgements, we may endorse Frege's account of being evident. But, how can inference rules be justified within Constructive Type Theory? When we want to understand the conjunction introduction rule, we first have to know how a proposition of the form $A \& B$ is explained in terms of its canonical proof(-object).

When $a$ is a proof of $A$ and $b$ is a proof of $B$, then the ordered pair $\langle a, b\rangle$ is a canonical proof of $A \& B$ (Martin-Löf 1984: 12).

The rule of \&-introduction is then:

$$
\begin{aligned}
& a: A \quad b: B \\
& \hline<a, b>: A \& B
\end{aligned}
$$

On the assumption that the premises are known (while assuming that $A$ and $B$ are propositions), and on the basis of the above explanation of conjunction, and with it our grasp of the proposition $A \& B$ in terms of what counts as a canonical proof for it, we see that we are entitled to make the judgement $\langle a, b\rangle: A \& B . .^{9}$ One has thus made the introduction-rule for conjunction evident to oneself. For someone who does not know yet what conjunction means, we may say, with Gentzen, that the introduction rule gives the meaning of conjunction. In this sense introduction rules can be understood as meaning giving. If someone is not willing to assert the conclusion under the assumption that the premises are known, one will have to say that he has not understood what conjunction is, and that there will be no way to communicate with him. There is no further guarantee that our inference rule is correct, as it is ultimately based on what we take to be self-evident, and thereby on our understanding of the terms involved. Does this mean that, after all, our justification of the inference rules, founded upon the notion of being (self-)evident as they are, implies a form of psychologism?

Robin Jeshion has proposed in her paper "On the Obvious" a distinction between a psychological notion of obviousness and an objective property of self-

9 I thank Göran Sundholm for giving me his notes relating to the subject. See also Martin-Löf 1983. 
evidence in order to account for the fallibility of our judgements of self-evidence: "Self-evidence is here taken to be the objective correlate of the subjective notion of obviousness" (Jeshion 2000: 354). Her account of self-evidence relates to truths, not to inference rules, but it can be easily extended to the justification of the inference rules proposed here.

According to Jeshion, "A proposition $\mathrm{p}$ is obvious to an agent $\mathrm{A}$ at time $\mathrm{t}$ [...] if and only if at $\mathrm{t} A$ finds $\mathrm{p}$ true on the basis of her [occurrent] conceptual understanding alone." (Jeshion 2000: 345). Because of the term “A finds $\mathrm{p}$ true at t', obviousness is a psychological notion, for finding something true at $t$ is not normative. Even if I now understand that $\mathrm{p}$ is not true, I can without contradiction admit that I found $\mathrm{p}$ true at a former time t. I am just describing a psychological fact about my past. Jeshion's notion of self-evidence is not explained in psychological terms: "a proposition $\mathrm{p}$ is self-evident if and only if understanding the concepts in p provides sufficient and compelling basis for recognition of p's truth.” (Jeshion 2000: 354). My criticism of her definition of self-evidence concerns two points. First, self-evidence does not pertain to the proposition as such: it is the truth of a proposition that is evident, as Frege put it. Or, as I prefer to put it, being evident pertains to judgements rather than to propositions. Second, there is a problem with the way Jeshion relates obviousness and self-evidence. According to Jeshion, obviousness can make us “a priori justified” (Jeshion 2000: 334). But, a psychological notion can never give us such a justification. In questions of being evident, the $\mathrm{A}$ for the agent and the t for the time of judging are irrelevant. These aspects of obviousness show that it is an empirical, psychological notion. And, if obviousness is a psychological notion, how can it provide an entitlement to take the proposition to be self-evident in any objective sense? The notion of obviousness is a third-person notion, an empirical factual phenomenon. Obviousness may be relevant when we ask a psychological question, for example: "For how many people is this obvious?". If being evident is at stake, our question is rather of the form: "Is it evident to me?" We thus see that being evident is a non-empirical, first person notion. We have to rely on an epistemic notion of being evident right from the start.

A good feature of Jeshion's account is that she allows for a role of the judging agent, but such a judging agent should not be understood in any psychological sense. When a judgement or an inference rule is evident to me, I take it that each judging agent is able to make it evident to himself. Being evident is in this sense objective. This notion of objectivity is neither independent of the notion of judging agent, nor does it provide a rock-bottom, for the judging agent can be mistaken. Being evident is essentially related to a first person. For, the fact that the judgement is evident to me gives no one else an entitlement to judge. Here, each agent has to see for himself; the most one can do is to give elucidations of the primitive notions to the reader. As Per Martin-Löf once put it: "there are also certain limits 
to what verbal explanations can do when it comes to justifying axioms and rules of inference. In the end, everybody must understand for himself." (Martin-Löf 1979: 166).

\section{Conclusion}

Essential to Frege's logic is the judgement stroke, and thereby the notion of judgement, and Frege is thus able to give an epistemic account of logic. Crucial notions in Frege's ideography, such as demonstration or justification and being evident, cannot be understood without invoking the notion of judgement stroke, and thereby that of the judging agent. As the judgement stroke is a sign of assertive force, it thus becomes clear that the notion of assertion has to play a central role in logic if one understands logic, like Frege, as an epistemic endeavour.

If one aims at an epistemic account of logic, as is done in Constructive Type Theory, one has to answer the question whether such epistemic notions as judgement, demonstration and being evident do not bring in a form of psychologism. This question is more easy to answer in the case of demonstration, because (traces of) demonstrations are found elsewhere in mathematical and logical texts, and each of us is thus able to make the demonstration, which gives demonstration the required objectivity, although it cannot be understood without invoking the notion of judging agent. The question is harder to answer in the case of being (self-)evident, but it needs to be answered because there will be no demonstration without our knowledge of the first principles and our knowledge of the inference rules.

Recently, philosophers like Robin Jeshion and Tyler Burge have proposed to make a distinction between a subjective counterpart to the notion of self-evidence, called obviousness, and an objective notion of self-evidence. The problem of this approach is that the psychological notion of obviousness does not give any entitlement to make an assertion, nor can it give us any entitlement to use the inference rules. Here it is argued that the psychological notion of obviousness is not to play a logical role at all. It is precisely because demonstration and self-evidence are normative notions that we can be mistaken: our claims to self-evidence are fallible. These notions cannot make sense without introducing the judging or knowing agent - each knowing agent has to make the first judgements and the inference rules evident to himself. This does not imply a form of psychologism, because the agent does not describe an empirical fact about himself when he claims a judgement or inference rule to be self-evident; it is rather that he thereby implicitly claims that any judging agent can make these judgements or inference rules evident 
to himself. In this sense, demonstration and self-evidence gain an independence from the empirical subject, although not any independence of the judging agent. ${ }^{10}$

\section{Bibliography}

Aristotle (1994): Posterior Analytics. Barnes, J. (ed.), second edition. Oxford: Clarendon Press, 1994.

Burge, Tyler (1998): “Frege on Knowing the Foundation.” In: Mind. Vol. 107, 305 - 347.

Frege, Gottlob (Bs): Begriffsschrift; eine der arithmetischen nachgebildete Formelsprache des reinen Denkens. In: Begriffsschrift und andere Aufsätze. Angelelli, I. (ed.). Hildesheim: Olms, $1971^{2}$ (1879).

Frege, Gottlob (GLA): Die Grundlagen der Arithmetik. Breslau: Koeber, 1884.

Frege, Gottlob (1885): Das Prinzip der Infinitesimal-Methode und seine Geschichte, Review of Cohen, H. In: KS, $99-102$.

Frege, Gottlob (1891): “Funktion und Begriff.” In: Funktion, Begriff, Bedeutung. Patzig, G. (ed.). Göttingen: Vandenhoeck \& Ruprecht, 1980, 18 - 39.

Frege, Gottlob (GG): Grundgesetze der Arithmetik. Hildesheim: Georg Olms, 1998 (1893). Facsimile of Jena: Hermann Pohle.

Frege, Gottlob (1896): “Über die Begriffsschrift des Herrn Peano und meine Eigene.” In: KS, 220 $-233$.

Frege, Gottlob (1923): “Gedankengefüge.” In: Beiträge zur Philosophie des deutschen Idealismus. Vol. 3, 36 - 51.

Frege, Gottlob (KS): Kleine Schriften. Angelelli, I. (ed.). Hildesheim: Olms, $1990^{2}$ (1967), 281 323.

Frege, Gottlob (WB): Wissenschaftliche Briefwechsel. Gabriel, G. et al. (eds.). Hamburg: Felix Meiner, 1976.

Frege, Gottlob (PW): Posthumous Writings. Hermes, H. et al. (eds.), Long, P.; White, R. (trans.). Oxford: Blackwell, 1979.

Frege, Gottlob (NS): Nachgelassene Schriften. Hermes, H. et al. (eds.). Hamburg: Felix Meiner, 1983.

Jeshion, Robin (2000): “On the Obvious.” In: Philosophy and Phenomenological Research. Vol. $40,333-355$.

Martin-Löf, Per (1979): “Constructive Mathematics and Computer Programming." In: Logic, Methodology and Philosophy of Science VI. Cohen, L.J.; Los, J.; Pfeiffer, H.; Podewski, K.P. (eds.), Proceedings of the 1979 international congress at Hannover. Amsterdam: NorthHolland Publishing Company, 1982, 153 - 175.

Martin-Löf, Per (1983): “On the Meaning of the Logical Constants and the Justifications of the Logical Laws.”, lectures held at Siena. In: Nordic Journal of Philosophical Logic. Vol. 1, 1996, $11-60$.

Martin-Löf, Per (1984): Intuitionistic Type Theory. Naples: Bibliopolis.

10 I am indebted to Göran Sundholm for extensive comments on two former versions of this paper. 
Martin-Löf, Per (2015): “Is Logic Part of Normative Ethics?” Lecture University of Utrecht, 16 April 2015 \& Paris, CNRS, 15 May 2015, manuscript.

Schaar, Maria van der (2011): "Assertion and Grounding: A Theory of Assertion for Constructive Type Theory.” In: Synthese. Vol. 183, 187 - 210.

Schaar, Maria van der (2018): “Frege on Judgement and the Judging Agent.” In: Mind. Vol. 127, $225-250$.

Shapiro, Stewart (2009): "We Hold these Truths to be Self-Evident: But what Do We Mean by That?" In: The Review of Symbolic Logic. Vol. 2, 175 - 207.

Sundholm, Göran (1988): Oordeel en Gevolgtrekking. Bedreigde Species? Inaugural lecture, Leiden.

Sundholm, Göran (1994): “Existence, Proof and Truth-Making: A Perspective on the Intuitionistic Conception of Truth.” In: Topoi. Vol. 13, 117-126.

Sundholm, Göran (2004): "Antirealism and the Roles of Truth." In:Handbook of Epistemology. Niiniluoto, I.; Sintonen, M.; Wolenski, J. (eds.). Dordrecht: Kluwer, 437 - 466.

Sundholm, Göran (2009): "A Century of Judgment and Inference, 1837-1936: Some Strands in the Development of Logic." In: The Development of Modern Logic. Haaparanta, L. (ed.). Oxford: Oxford University Press, 263 - 317.

Sundholm, Göran (2011): “A Garden of Grounding Trees.” In: Logic and Knowledge. Cellucci, C.; Grosholz, E.; Ippoliti, E. (eds.). Newcastle upon Tyne: Cambridge Scholars Publishing, 57 74.

Williamson, Timothy (2000): Knowledge and its Limits. Oxford: Oxford University Press.

Wittgenstein, Ludwig (TLP): Tractatus. In: Werkausgabe, Band 1. Frankfurt am Main: Suhrkamp, 1984 (1921).

Wittgenstein, Ludwig (ÜG): Über Gewissheit. In: Werkausgabe, Band 8. Frankfurt am Main: Suhrkamp, 1984 (1951). 